\title{
Five Osteosarcoma of the Lower Extremity Treated by Rotationplasty: University of the Philippines - Philippine General Hospital Experience
}

\author{
Phillip Aristotle R. Hermida, MD, ${ }^{*}$ Cesar D. Dimayuga, MD* and Albert Jerome D. Quintos, MD \\ Department of Orthopedics, Philippine General Hospital, University of the Philippines Manila
}

\begin{abstract}
Functional and oncologic results of the initial series of children with osteosarcoma treated with rotationplasty at the University of the Philippines - Philippine General Hospital from 2014 to 2015 are reported. Five children (mean 13.2 years) with Enneking IIB osteosarcoma of the lower extremity underwent neoadjuvant chemotherapy, tumor resection with wide margins, and rotationplasty - four Winkelmann Type Al and one Type All. The four Type-A cases were fixed using an intramedullary nail and the Type A2 case with a plate. Two cases had $>90 \%$ tumor necrosis. Adjuvant chemotherapy was started 10 to 21 days following surgery. Functional results for the Al rotationplasty showed a good range of motion of the ankle (neo-knee) with preserved muscle strength. The patient with All rotationplasty had a fair range of motion of the ankle with some muscle weakness. All had radiographic evidence of healing at an average of 12 weeks. The oncologic outcome showed two with local recurrences at five months from surgery; three died of disease at 7, 20, and 38 months; while two are alive without evidence of disease at 72 and 84 months. Three patients were able to fit with a prosthesis with good utility, ambulation status, and satisfaction.
\end{abstract}

Keywords: Osteosarcoma, rotationplasty, Van Nes

${ }^{*}$ Dr. Hermida and Dr. Dimayuga shared first authorship for this paper.

Corresponding author: Phillip Aristotle R. Hermida, MD Department of Orthopedics Philippine General Hospital University of the Philippines Manila Taft Avenue, Ermita, Manila 1000, Philippines Email: lordhermida@gmail.com

\section{BACKGROUND}

Osteosarcoma is the most common primary malignant tumor of bone. It is characterized by a proliferation of malignant mesenchymal cells that produce osteoid or immature bone. The peak incidence occurs in the second decade of life, with $75 \%$ of cases seen between 10 and 25 years old Wang and de Dios reviewed 231 cases of osteosarcoma in Filipinos and found that $66 \%$ were between 11 to 20 years old, with male preponderance $(61.5 \%) \cdot{ }^{1-4}$

Eighty to ninety percent of the tumor occurred in the metaphysis of long bones and, in most cases, extend to the epiphysis. The most frequent areas were the distal femur (35\%), proximal tibia (20\%), and proximal humerus (10\%). Philippine data showed 49\% with distal femur affectation, and $22 \%$ were seen in the proximal tibia. ${ }^{4}$ Treatment for osteosarcoma includes both chemotherapy and surgical removal of the tumor. Surgical options of osteosarcoma around the knee include 1) tumor resection with at least wide oncologic margins and limb salvage, 2) at least an aboveknee amputation, and 3) rotationplasty. ${ }^{2,3,5}$ Rotationplasty is a unique procedure in which the knee joint is removed along with the tumor, the lower leg is rotated 180 degrees, and the remaining tibia fixed to the thigh. The ankle joint then acts as a converted knee joint. This procedure is low cost, functional and permanent, which makes it an ideal procedure for osteosarcoma patients in developing countries. ${ }^{1,6}$ 


\section{REVIEW OF LITERATURE}

Before 1970, the treatment of osteosarcoma in the distal part of the femur or the proximal part of the tibia was either an above-knee amputation (transfemoral) or a hip disarticulation. Around $80 \%$ succumbed to death from metastases, primarily to the lungs. Since then, treatment with surgery combined with chemotherapy improved survival to approximately $60-70 \%$. Treatment begins with accurate clinical staging followed by histopathologic diagnosis through a properly performed biopsy. The current standard of treatment is neoadjuvant chemotherapy composed of multiagent drug therapy followed by surgery, which is either limb salvage or an ablative procedure, and completed with adjuvant chemotherapy. ${ }^{2,5,7-12}$

Bacci et al. reported five-year disease-free survival and overall survival rates $(60.7 \%$ and $68.5 \%)$ with no significant difference between patients undergoing amputation and those undergoing resection. ${ }^{11}$ Nagarajan et al. reported $88.6 \%$ overall survival of children who survived five years at 20 years from original diagnosis. ${ }^{8}$ Yonemoto found that the prognosis of osteosarcoma with pulmonary metastases at initial presentation is not dismal, with a 5-year survival rate of $64.8 \%{ }^{13}$

Rotationplasty is a surgical method in which the ankle joint is used to function as the knee joint. Following segmental resection of the knee joint, the leg is rotated $180^{\circ}$ onto the thigh and fixed for osteosynthesis. ${ }^{13,14}$ It is indicated for patients wherein a wide margin can be obtained, and major neurovascular structures can be safely spared. Rotationplasty was first performed by Borggreve in 1927 for a patient with tuberculosis but was popularized by van Nes in 1950 when he used the procedure for congenital femoral deficiencies. Salzer and Knahr first used the procedure to reconstruct a tumor defect around the knee for osteosarcoma and is currently the most common indication for this procedure. It has evolved over the years and is now performed for malignant lesions involving the distal femur, proximal femur, entire femur, the upper part of the tibia, hip, and acetabulum., ${ }^{2,6}$

In terms of function, rotationplasty is superior to an above-knee amputation and similar to tumor endoprosthesis (megaprosthesis). Rotationplasty patients have good restoration of gait and have less pain, and they can participate in hobbies and sports more often than megaprosthesis patients. Gait analysis in several studies shows that patients who undergo endoprosthesis replacement consume less oxygen than those who had an amputation but equivalent with rotationplasty. ${ }^{8,9,15}$ Furthermore, rotationplasty is a low-cost, one-time, permanent, and functional reconstruction method, making it a useful treatment option. Endoprosthesis/ megaprosthesis is expensive and may, in the long term, require revision or additional surgery. ${ }^{6,7}$

Catani et al. assessed the gait of the children who underwent rotationplasty. They found differences in speed and stride length, but the gait of children who underwent rotationplasty surgery was similar to normal children. ${ }^{2}$ Hillmann et al. showed patients have good functional restoration of gait evaluated by electromyographic and gait analysis. ${ }^{15}$ Yoshida et al. demonstrated good use of prostheses where patients scored $100 \%$ for walking, gait, and function. They also found an 81\% MSTS score (Musculoskeletal Tumor Society). ${ }^{16}$

This study aims to present the initial series of rotationplasty in the distal femur and proximal tibia osteosarcoma patients in 2014 - 2015 at the University of the Philippines-Philippine General Hospital (UP-PGH) in terms of functional and oncologic outcomes.

\section{PATIENTS AND METHODS}

In 2014 and the first quarter of 2015, five children, with a mean age of 13.2 years, with osteosarcoma of the knee underwent rotationplasty at the Department of Orthopedics of the UP-PGH. Four children had osteosarcoma of the distal femur, while one had proximal tibial involvement. Three presented with a palpable mass, and two experienced severe pain caused by a pathologic fracture of the diseased long bone. All patients were staged as Enneking IIB. Each patient received at least two cycles of neoadjuvant chemotherapy with cisplatinum and adriamycin (CDDP/ ADR) before the procedure at 4-week intervals.

Surgical planning was carried out using plain radiographs and post-neoadjuvant chemotherapy magnetic resonance imaging. The expected growth discrepancy between the lower extremities was estimated using the Paley growth calculation for very young patients. Resection of the tumor was done with wide surgical margins. The four children with distal femoral lesions underwent Winkelmann Type IA rotationplasty, where intramedullary nail fixation was used. The patient with proximal tibial lesion underwent Type IIA rotationplasty with plate fixation. For patients with significant growth left, the rotationplasty extremity was left a few $\mathrm{cm}$ longer than the contralateral bent knee. (Appendix - Surgical Technique). The average operation time was 11.3 hours with $1150 \mathrm{ml}$ blood loss. Each received an average of three units packed RBC. The first patient to undergo rotationplasty (JS) stayed at the Pediatric intensive care unit for three days while the succeeding four children returned to the ward uneventfully. There were no early (lower-limb ischemia, skin necrosis, superficial/deep infection) nor late (nonunion, malrotation, fracture, deep infection, and nerve palsy) complications.

All five specimens were sent for histopathologic studies, which were all read as osteoblastic osteosarcoma. Tumor necrosis of the resected specimen was determined. Three patients were poor responders (tumor necrosis $<90 \%$ ), the other two were good responders (tumor necrosis >90\%). Adjuvant chemotherapy, to complete the total recommended six cycles, using the same chemo regimen, was started 10 to 21 days following surgery after wound healing. One patient 
Table 1. Patient Demographics of Osteosarcoma Patients Treated with Rotationplasty

\begin{tabular}{cccccccccc}
$\begin{array}{c}\text { Patient } \\
\text { Code }\end{array}$ & Sex & $\begin{array}{c}\text { Age at } \\
\text { Procedure }\end{array}$ & $\begin{array}{c}\text { Enneking } \\
\text { Stage }\end{array}$ & $\begin{array}{c}\text { Date of } \\
\text { Procedure }\end{array}$ & $\begin{array}{c}\text { Winkelmann } \\
\text { Type }\end{array}$ & $\begin{array}{c}\text { Implant } \\
\text { Used }\end{array}$ & $\begin{array}{c}\text { NeoAdj Chemo Cycles } \\
\text { (CDDP/ADR)** }\end{array}$ & $\begin{array}{c}\text { Tumor } \\
\text { Necrosis (\%) }\end{array}$ & $\begin{array}{c}\text { Adjuvant Chemo } \\
\text { Cycles (CDDP-ADR) }\end{array}$ \\
JS & M & 14 & IIB & $05 / 27 / 2014$ & Al & IM Nail* & 3 & 98 & 3 \\
JR & M & 18 & IIB & $08 / 29 / 2014$ & Al & IM Nail & 4 & 70 & 2 \\
MM & M & 16 & IIB & $10 / 03 / 2014$ & Al & IM Nail & 5 & 35 & 1 \\
CM & F & 8 & IIB & $02 / 03 / 2015$ & Al & IM Nail & 3 & 65 & 3 \\
CE & M & 10 & IIB & $03 / 27 / 2015$ & All & Plate & 6 & 60 & 2 \\
\hline
\end{tabular}

${ }^{*}$ IM Nail - Intramedullary Nail, ${ }^{* *} C D D P-A D R$ - cisplatinum / adriamycin

Table 2. Musculoskeletal Tumor Society Scores

\begin{tabular}{cccccc} 
Patient code & JS & JR & MM & CM & CE \\
Pain & 5 & 5 & Tumor & 5 & 5 \\
Function & 4 & 5 & recurrence & 4 & 4 \\
Emotional & 4 & 5 & March 2015 & 4 & 4 \\
Support & 4 & 3 & Expired & 3 & 3 \\
Walking & 5 & 4 & May 2015 & 4 & 4 \\
Gait & 4 & 3 & & 5 & 5 \\
\hline Total & $\mathbf{2 6 / 3 0}$ & $\mathbf{2 5 / 3 0}$ & & $\mathbf{2 5 / 3 0}$ & $\mathbf{2 5 / 3 0}$ \\
\hline Percentage & $\mathbf{8 7 \%}$ & $\mathbf{8 3 \%}$ & & $\mathbf{8 3 \%}$ & $\mathbf{8 3 \%}$ \\
\hline
\end{tabular}

had delayed surgery and received six cycles of neoadjuvant chemotherapy and two cycles of adjuvant treatment. (Table 1)

These children were followed for a minimum of 6 months post-surgery. The range of motion of the ankle (neoknee) and muscle strength was measured. Radiographic union was assessed at 4-week intervals. Functional outcomes were measured using the Musculoskeletal Tumor Society Score and the European Organization for Research and Treatment of Cancer QLQ-C30 (EORTC QLQ-C30). The second measurement tool had been translated into more than 100 languages and validated, including Filipino.

\section{RESULTS}

\section{Functional Outcome}

Functional results for the AI rotationplasty showed a good postoperative active range of motion of the ankle (neoknee) 0-40/50 degrees of plantar flexion and 0-10/20 degrees dorsiflexion with preserved muscle strength (5/5). The patient with AII rotationplasty had a fair range of motion of the ankle (neo-knee) with 0-30 plantar flexion and 0-10 dorsiflexion with some muscle weakness (4/5)

For the skeletally mature patients, the end of the rotationplasty extremity, which is the plantar heel, was made equal to the anterior portion of the bent knee of the contralateral limb. For the two skeletally immature patients, to provide for the predicted remaining growth of the normal lower extremity, the rotationplasty extremity was left a few $\mathrm{cm}$ longer.

Radiographic evidence of healing was present in all cases at an average of 12 weeks. Three patients received a custom-fit prosthesis three months post-surgery and underwent physical therapy and gait retraining. All three used the prosthesis well, one until his demise four and a half years postsurgery, and the other two continue to use their prosthesis as of their latest follow-up six and seven years post-surgery. The two patients who were not fitted with a prosthesis developed local tumor recurrence around four months post-surgery.

The MSTS scores with an average of $84 \%$ are shown in Table 2, while Table 3 summarized the EORTC QLQC30 scores.

\section{Oncologic Outcome}

Two are alive with no evidence of disease at six and seven years after the surgery. There were two with local recurrence. One developed lung metastasis within a month of surgery had local recurrence at the gluteal area at five months and expired seven months postoperatively. The other one with the Type AII rotationplasty had local recurrence at the distal leg within five months, initially without lung metastases. $\mathrm{He}$ was managed with an above-knee amputation. He developed lung metastasis the following year and succumbed to the disease 20 months post-surgery. One case developed progression of the disease over four years after surgery and developed lung metastasis and eventually died of his condition. None died of other complications. (Table 4)

\section{DISCUSSION}

Two of the most unsatisfactory outcomes have tumor necrosis of $60-65 \%$ only, while the third mortality had tumor necrosis of $70 \%$. Possible reasons for this are the high tumor activity and perhaps resistance to chemotherapy. None of the five patients followed the planned schedule for chemotherapy and surgery protocol correctly. Guidelines were set to give two cycles of Cisplatinum and Adriamycin at a 4-week interval followed by surgery within two weeks after the second cycle. Adjuvant therapy of four cycles should ensue within two to three weeks post-surgery. Factors for the poor adherence to the protocol include economic capabilities of the family (cost of drugs, transportation, and hospital stay), lack of infrastructure (limitation of accommodation at the cancer ward, availability of surgical slots), social support (absence of a responsible guardian among others), and patient factors (patient not cleared for surgery due to side effects of 
Table 3. European Organization for Research and Treatment of Cancer Quality of Life Questionnaire - C30

\begin{tabular}{|c|c|c|c|c|c|c|c|c|}
\hline \multirow[b]{2}{*}{ Patient code } & \multicolumn{4}{|c|}{ Raw Score $(x, \pm S D)$} & \multicolumn{4}{|c|}{ Score $(x, \pm$ SD) } \\
\hline & JS & $\mathbf{J R}$ & $\mathrm{CM}$ & Mean & JS & JR & CM & Mean \\
\hline Global Health Status & 7 & 5 & 6.5 & 6.17 & 100 & 66.67 & 91.67 & 86.45 \\
\hline \multicolumn{9}{|l|}{ Functional Scales } \\
\hline Physical & 1.2 & 1.4 & 1.2 & 1.27 & 93.33 & 86.67 & 93.33 & 91.11 \\
\hline Role & 1 & 1.5 & 1 & 1.17 & 100 & 83 & 100 & 94.33 \\
\hline Emotional & 1.75 & 1 & 1 & 1.25 & 75 & 100 & 100 & 91.67 \\
\hline Cognitive & 1 & 2 & 1 & 1.33 & 100 & 66.67 & 100 & 88.89 \\
\hline \multirow[t]{2}{*}{ Social } & 1 & 1 & 1 & 1 & 100 & 100 & 100 & 100 \\
\hline & & & & & & & & 93.2 \\
\hline \multicolumn{9}{|l|}{ Symptom Scales / Items } \\
\hline Fatigue & 1.66 & 2.33 & 1 & 1.67 & 22.22 & 44.44 & 0 & 22.22 \\
\hline Nausea and Vomiting & 1 & 1 & 1 & 1 & 0 & 0 & 0 & 0 \\
\hline Pain & 1 & 1.5 & 1 & 1.17 & 0 & 16.67 & 0 & 5.57 \\
\hline Dyspnea & 1 & 1 & 1 & 1 & 0 & 0 & 0 & 0 \\
\hline Insomnia & 1 & 1 & 1 & 1 & 0 & 0 & 0 & 0 \\
\hline Appetite Loss & 1 & 1 & 1 & 1 & 0 & 0 & 0 & 0 \\
\hline Constipation & 1 & 1 & 1 & 1 & 0 & 0 & 0 & 0 \\
\hline Diarrhea & 1 & 1 & 1 & 1 & 0 & 0 & 0 & 0 \\
\hline \multirow[t]{2}{*}{ Financial Difficulties } & 1 & 4 & 2 & 2.33 & 0 & 100 & 33.33 & 44.33 \\
\hline & & & & & & & & 8.01 \\
\hline
\end{tabular}

Table 4. Patient Follow-up Outcomes

\begin{tabular}{cccccc} 
Patient Code & $\begin{array}{c}\text { Length of follow-up } \\
\text { from Surgery (Months) }\end{array}$ & $\begin{array}{c}\text { Local Recurrence Location, } \\
\text { (months post-op) }\end{array}$ & $\begin{array}{c}\text { Metastasis Location } \\
\text { (months post-op) }\end{array}$ & $\begin{array}{c}\text { Oncologic Status } \\
\text { (months post-op) }\end{array}$ & $\begin{array}{c}\text { Prosthesis fitted } \\
\text { and used }\end{array}$ \\
JS & 84 & none & none & ANED* & yes \\
JR & 54 & none & Lungs (51) & DOD (54) & yes \\
MM & 7 & gluteal area (5) & Lungs (1) & DOD (7) & no \\
CM & 72 & none & none & ANED & DOD (20) \\
CE & 20 & distal leg (5) & Lungs (18) & no \\
\hline
\end{tabular}

${ }^{*} A N E D$ - alive with no evidence of disease, DOD - dead of disease

chemotherapy, such as febrile neutropenia). It is noted that the patients with the poor chemotherapy response in terms of tumor necrosis also had neoadjuvant treatment higher than three cycles. One may theorize that this may contribute to the chemoresistance of the tumor.

The use of intramedullary nails over a plate was not only proper but convenient as well. There was less soft tissue stripping of the remaining bone with nailing versus plating. The long bones of four patients accommodated a regularsized nail, but one had a narrow medullary canal which precluded its use. A $4.5 \mathrm{~mm}$ narrow dynamic compression plate was used instead.

Hillmann et al. showed that most patients who underwent rotationplasty (83\%) had excellent MSTS scores. Only $17 \%$ of patients had fair and poor satisfaction. The average MSTS score in their study was $23.9 \pm 2.7 .{ }^{14}$ The current series had an average of 25.4 or $84 \%$. Using the European Organization for Research and Treatment of Cancer Quality of Life Questionnaire-C30, these patients had good global health status (86.45) and an excellent functional score of
93.2. This represents a high quality of life and a high level of functioning. The reverse is true for the symptoms scale, where a high score represents a high level of problems. In this study, the average symptom score was 8.01. This means our patients had a low level of symptoms. The factor which contributed most to the symptom score was financial difficulties.

All osteotomies went into the union at an average of 12 weeks follow-up. The range of motion of ankle and muscle strengths was better preserved in the Winkelman AI rotationplasty patients than the AII patient. This may be expected as the muscles needed to move the ankle or neo-knee are not transected in these cases. No early or late complications were reported.

The results of our initial series are encouraging. Our institution will continue to perform such procedures whenever indicated. There is, however, a need to improve on identified limitations to the delivery of care to ensure proper dosing schedule of multi-agent neoadjuvant and adjuvant chemotherapy and proper timing of the surgery. The importance of a multidisciplinary approach cannot be 
overemphasized. Careful evaluation by musculoskeletal tumor specialists, medical and pediatric oncologists, physiatrists and prosthetists, psychiatrists and active involvement of the patient and the family in the pretreatment planning, delivery of chemotherapy, surgical management well as postoperative care account for safe, timely, and effective delivery of treatment and successful outcomes. Overall, rotationplasty is a low-cost and viable option for selected osteosarcoma patients in developing countries.

\section{Acknowledgment}

Dr. Edward HM Wang (Chairman Emeritus) and Dr. Rex Peñaranda of Southern Philippines Medical Center for the technical assistance during the initial stages of this study.

\section{Statement of Authorship}

All authors participated in the data collection and analysis and approved the final version submitted.

\section{Author Disclosure}

All authors declared no conflicts of interest.

\section{Funding Source}

No funding support.

\section{REFERENCES}

1. Yang JYK, Cheng FWT, Wong KC, Lee V, Leung WK, Shing MMK, et al. Initial presentation and management of osteosarcoma and its impact on disease outcome. Hong Kong Med J. 2009;15:434-9.

2. Gibbs CP, Weber K, Scarborough MT. Malignant bone tumors. JBJS. 2001;83-A(11).

3. Ritter J, Bielack SS. Osteosarcoma. Ann Oncol. 2010; (Supplement 7): vii320-vii325

4. Wang E, de Dios V. Bone Tumors in Filipinos. 2007.
5. Hogendoorn PCW, Athanasou N, Bielack S, De Alava E, Dei Tos AP, Ferrari S, et al. Bone sarcomas: ESMO Clinical Practice Guidelines for diagnosis, treatment, and follow-up. Ann Oncol. 2010; (Supplement 5): v204-v213.

6. Agarwal M, Puri A, Anchan C, Shah M, Jambhekar N. Rotationplasty for Bone Tumors. Is There Still a Role? Clin Orthop Relat Res. 2007;459:76-81.

7. Jeffree GM, Price $\mathrm{CH}$, Sissons HA. The metastatic patterns of osteosarcoma. Br J Cancer. 1975;32:87-107.

8. Nagarajan R, Kamruzzaman A, Ness KK, Marchese VG, Sklar C, Mertens A, et al. Twenty Years of Follow-Up of Survivors of Childhood Osteosarcoma, A Report From the Childhood Cancer Survivor Study. Cancer. 2011; 625-34.

9. Sawamura C, Hornicek FJ, Gebhardt MC. Complication and Risk for Failure of Rotationplasty. Clin Orthop Relat Res. 2008; 466:1302-8.

10. Po KW, Wei MC, Cheng FC, Lee OK, Ching KH, Tain HC, et al. Primary Osteogenic Sarcoma with Pulmonary Metastasis: Clinical Results and Prognostic Factors in 91 Patients. Jpn J Clin Oncology. 2009;39(8)514-22.

11. Bacci G, Ferrari S, Lari S, Mercuri M, Donati D, Longhi A, et al. Osteosarcoma of the limb: Amputation or Limb Salvage in Patients Treated by Neoadjuvant Chemotherapy. J Bone Joint Surg [Br] 2002;84-B:88-92.

12. Munajat I, Zulmi W, Norazman MZ, Faisham WIW. Tumour volume and lung metastasis in patients with osteosarcoma. J Orthop Surg Res. 2008;16(2):182-5.

13. Yonemoto T, Tatezaki S, Ishii T, Satoh T, Kimura H, Iwai N. Prognosis of osteosarcoma with pulmonary metastases at initial presentation is not dismal. Clin. Orthop. Relat. Res. 1998;349:194-9.

14. Hillmann A, Hoffmann C, Gosheger G, Krakau H, Winkelmann W. Malignant tumor of the distal part of the femur or the proximal part of the tibia: endoprosthetic replacement or rotationplasty. Functional Outcome and Quality-of-Life Measurements. J Bone Joint Surg. 1999;81:462-8.

15. Hillmann A, Rosenbaum D, Schroter J, Gosheger G, Hoffmann C, Winkelmann W. Electromyographic and Gait Analysis of Fortythree Patients After Rotationplasty. J Bone Joint Surg. 2000;82-A(2): 187-96.

16. Yoshida Y, Osaka S, Tokuhashi Y. Analysis of limb function after various reconstruction methods according to tumor location following resection of pediatric malignant bone tumors. World J Surg Onc. 2010, (8):(39) 


\section{APPENDIX}

\section{Surgical Techniques}

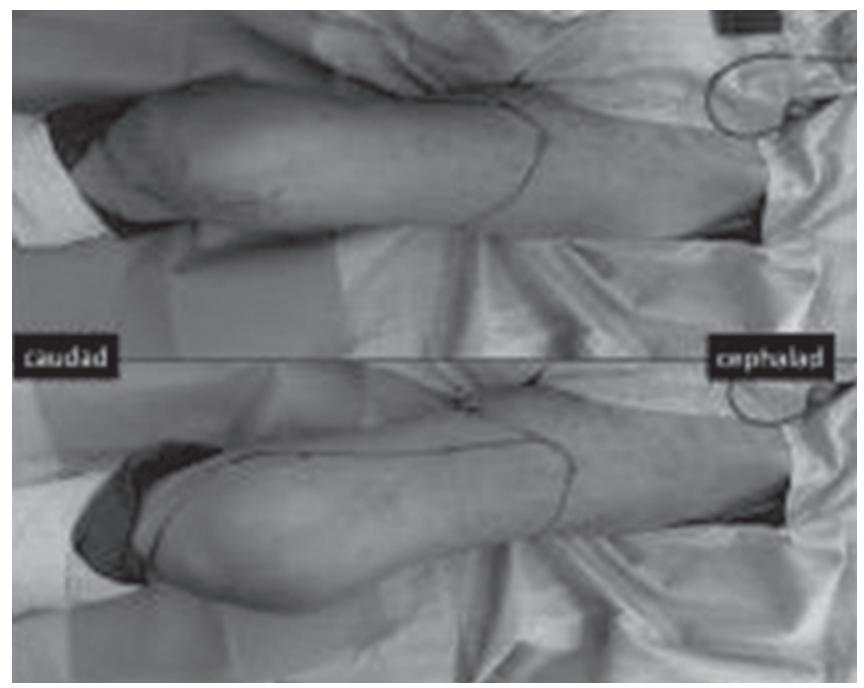

Figure 1. Incisions consisting of two oblique ellipses. The thigh is wider than the leg; therefore, the slope of the distal incision is greater than that of the proximal incision to ensure that the circumference of both incisions is equal.
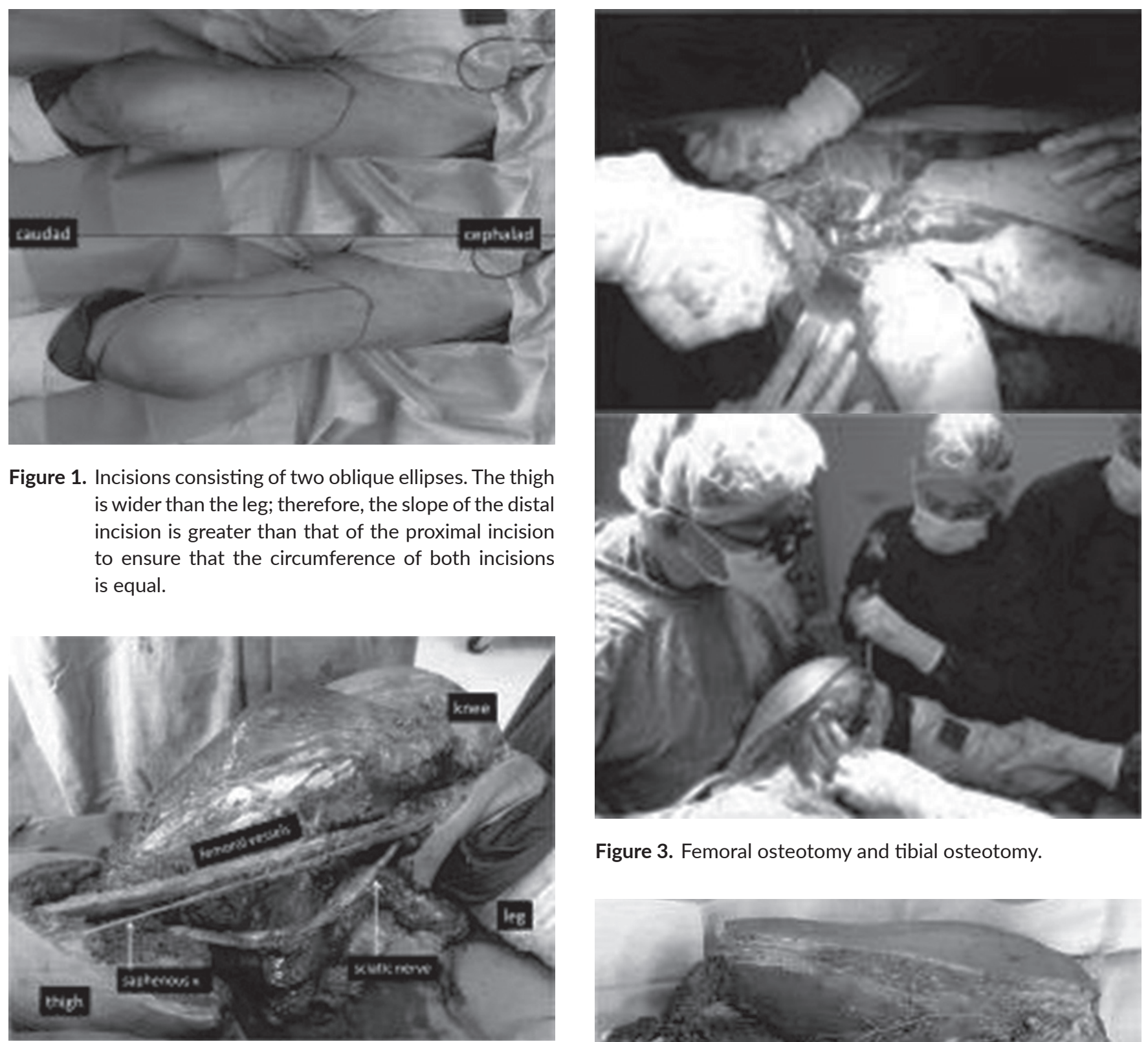

Figure 3. Femoral osteotomy and tibial osteotomy.

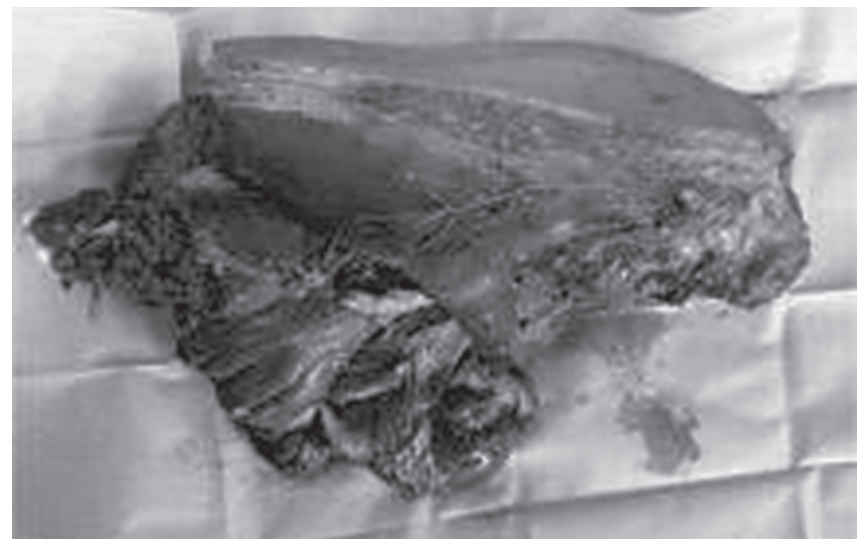

Figure 4. The intercalary segment is then removed, and the distal segment is externally rotated $180^{\circ}$ while ensuring that the neurovascular structures can move medially without tension. 


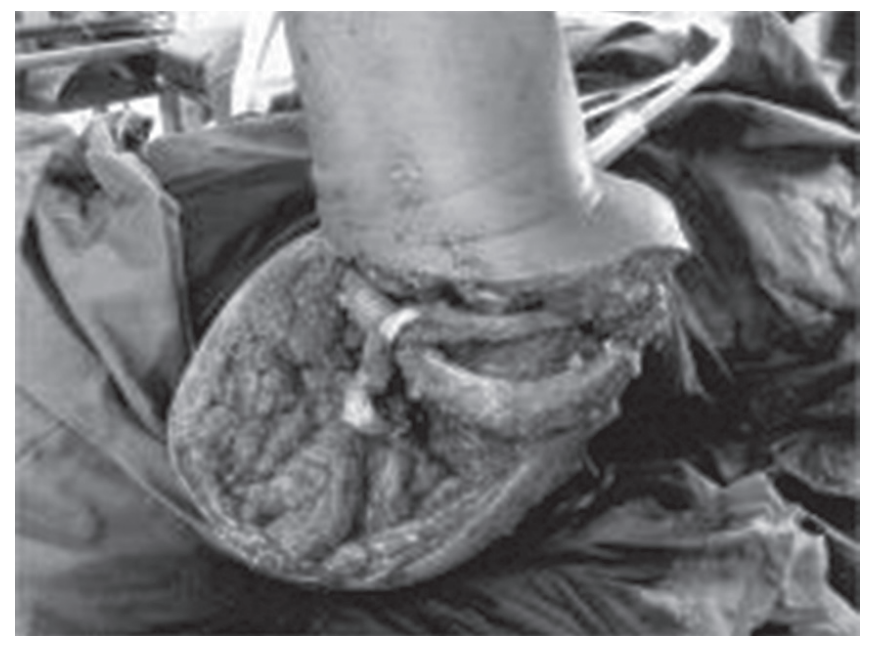

Figure 5. The vessels and nerve are coiled carefully to prevent kinks and are then placed within a soft-tissue bed in the anteromedial thigh. The investing fascia is not closed to reduce the risk of compartment syndrome. The skin is approximated with staples, and any excess skin is removed approximated with staples, and any excess skin is removed.
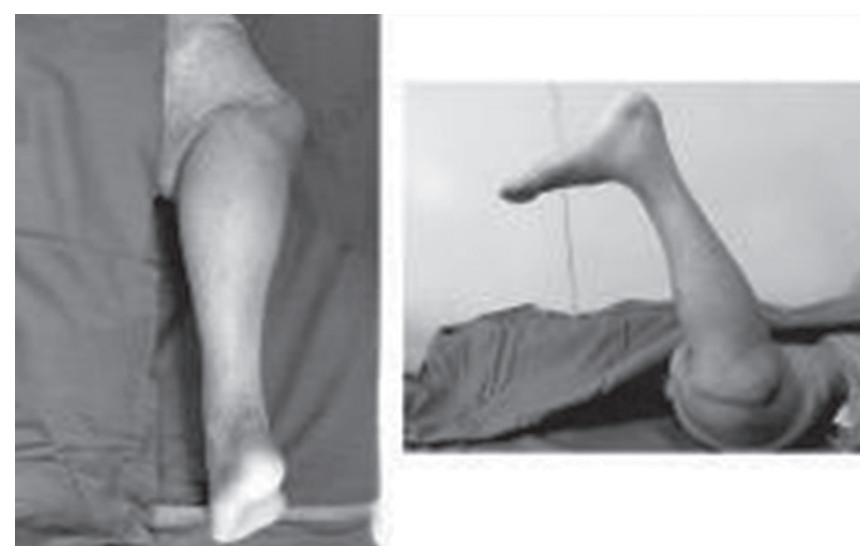

Figure 6. Post-op range of motion of hip and ankle (knee).

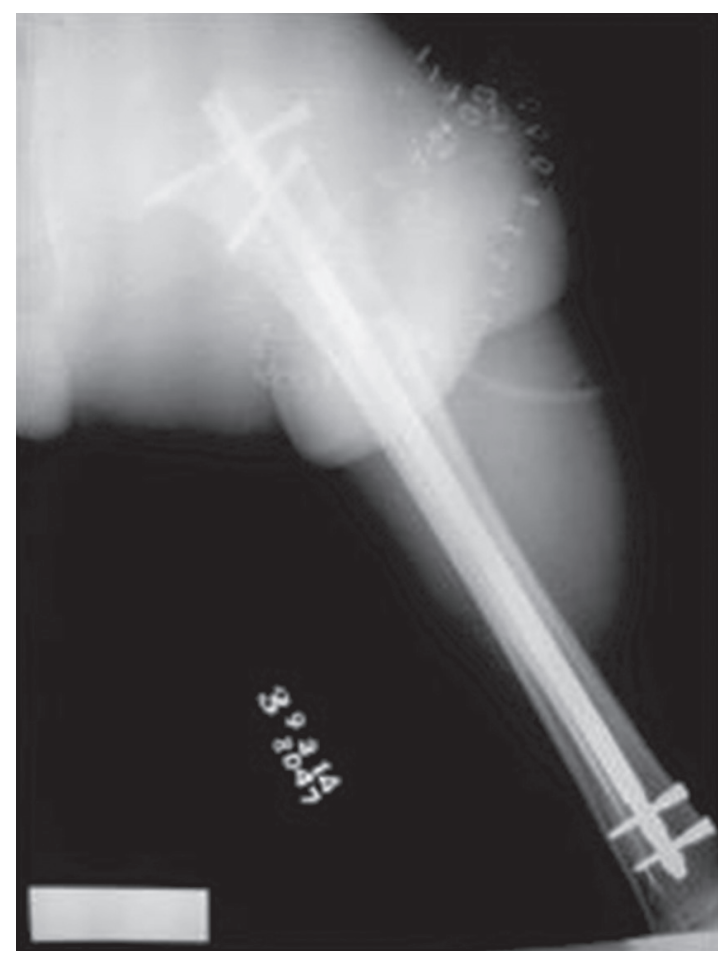

Figure 7. Osseous fixation with intramedullary nail.

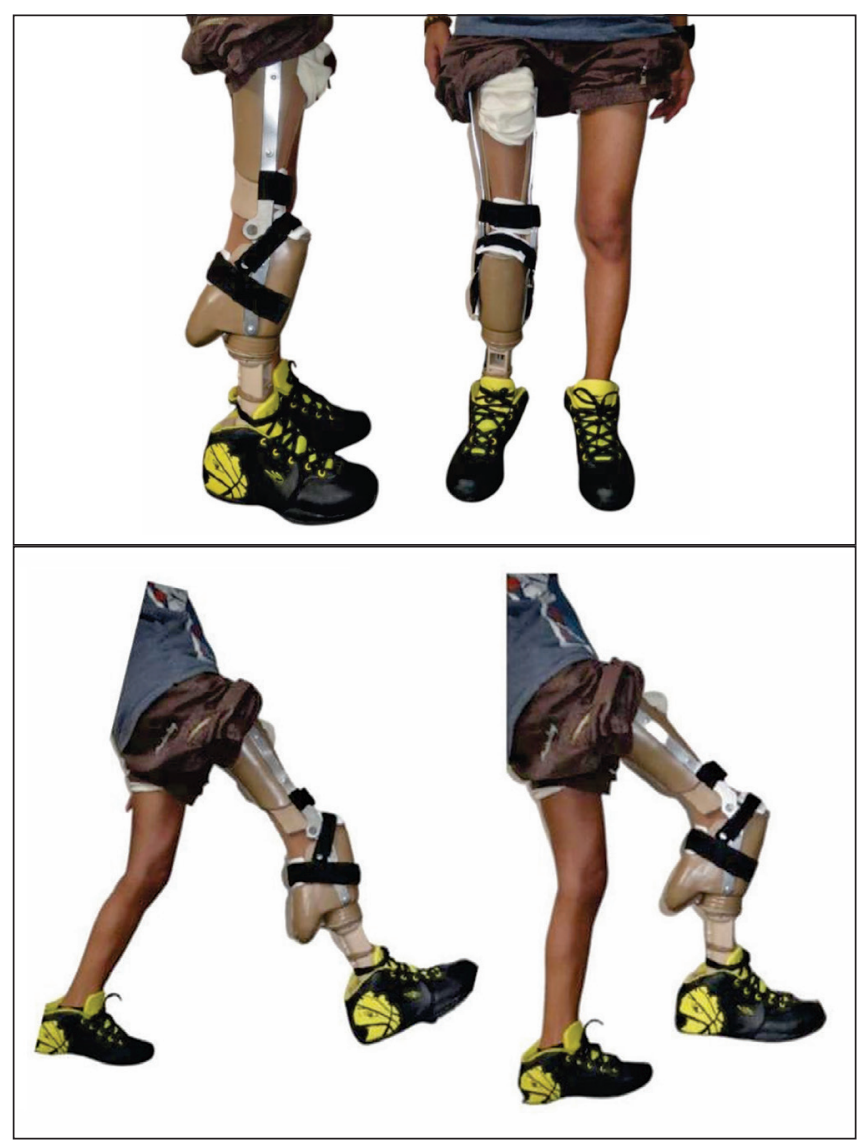

Figure 8. Patient JS with rotationplasty prosthesis. 